\title{
LdShake support for team-based learning design
}

\author{
Davinia Hernández-Leo (*), Pau Moreno, Jonathan Chacón, Josep Blat \\ Department of Information and Communication Technologies, Universitat Pompeu Fabra, Barcelona, Spain \\ (*) Corresponding author. Address: Roc Boronat 13808018 Barcelona, Spain. Tel.: + 34935421428. \\ E-mail address: davinia.hernandez@upf.edu
}

\begin{abstract}
Some educational innovation initiatives require practitioners to team up on the design of new learning activities. However, existing learning design tooling does not integrally support their tasks. Some tools enable authoring of designs, while other tools support sharing and commenting of learning design ideas, but none of them offer an integrated provision of technological features to support learning design team-based work requirements. These requirements include team formation, the storage and retrieval of designs, and the promotion of interaction in the co-creation of designs. The LdShake platform has been conceived to enable sharing and co-editing of learning designs. This paper introduces LdShake's technological features and evaluates to what extent they support the aforementioned requirements. $A$ first evaluation context is genuinely focused on learning design, while a second is devoted to devising research ideas. The results obtained in the two contexts are complementary, pointing out distinct affordances and user behaviours (e.g., on browsing designs) that depend on the characteristics of each context, while also bringing to light the relevance of LdShake's social network related features. Overall, the proposed design considerations in LdShake's technological features and the obtained evaluation results contribute towards an improved understanding of how to support networked teams.
\end{abstract}

\section{Keywords}

Networked teams, learning and innovation, sharing, co-editing, learning design, research design

\section{Introduction}

The reasons and motivations for teams of teachers to collaboratively create learning designs are diverse. In the context of Higher Education, integrated or transversal courses have been gaining importance, as they require students to integrate and apply the knowledge they have acquired in other courses into a multi-disciplinary or comprehensive scenario. Usually, educators coming from several disciplines or courses participate in the preparation of these kinds of pedagogically innovative crosscutting activities. An example of this approach at the Universitat Pompeu Fabra is the Human Biology Degree curriculum that includes a set of "integrated courses" that follow a Problem-Based Learning (PBL) methodology. The proposed problems include aspects from different courses that students have previously studied. Therefore, educators in charge of these courses need to collaboratively design integrative problems (Carrió, Larramona, Baños, \& Pérez, 2011). It is also common to find crosscutting activities in Primary and Secondary education, usually in the form of thematic workshops, which are comprised of sub-activities related to different subjects, and that require teachers to work creatively and in teams (Goddard, Goddard, \& Tschannen-Moran, 2007).

The scale of these activities is often restricted to one centre only, involving just one school or university. However, there are also cases of collaborations emerging outside the confines of a centre. These collaborations are particularly well regarded by the educational community as inter-centre collaborations that foster the exchange of experiences. Participating educators learn from colleagues who may have different points of view about the subject matter, or who come from centres that present completely different situations in terms of the student community they serve (e.g., rural vs. city life). These initiatives are usually framed in the context of teaching innovation projects and the collaboration between educators in different centres is expected to result in innovative educational programs, activities, and materials (Kozma, 2003; Lope, 2009; Williams \& Thorpe, 1998). However, the thriving of these initiatives often become especially challenging due to the physical distance between the teachers, the fact that they sometimes plan learning activities at home (Michelson \& Harvey, 2000), or simply because of scheduling problems.

Therefore, these initiatives would benefit from software tools supporting on-line team-based work 
requirements of the larger context of learning design. These requirements include team formation within eventually larger communities of educators, the storage and retrieval of shared designs and the enabling and promoting of interactions between educators (and other stakeholders) in the process of co-creating the designs. A number of tools have been developed to support the creation of learning designs; however, they only satisfy some of these requirements. On the one hand, educational technology specification (such as IMS Learning Design, LD) compliant editors have provided a common format for the designs and enabled interoperability (Griffiths \& Blat, 2005). Visual editors compliant with LD or other educational modelling languages have been also proposed (Conole, forthcoming) though they do not provide the means for teachers to share the designs, nor do they support design co-creation between different educators (Neumann et al., 2010). Additionally, a number of existing authoring tools support collaborative edition and have proved to improve teams' coordination, productivity and quality of the results (Calvo, O'Rourke, Jones, Yacef \& Reimann, 2011). Nevertheless, these co-editors are not specifically focused on learning design and do not provide technological features to support team formation and storage, and the retrieval of shared productions. On the other hand, several tools have been proposed to address the problem of sharing educational resources from different perspectives, always separately from the co-authoring problem. GLOW (2011), Agrega (Sarasa, Canabal, \& Sacristán, 2009) or EdShare (Davis et al., 2010), among many others, are examples of resource repositories, whereas AUTC (2003), Phoebe (2011) and CloudWorks (Conole, forthcoming) store and classify learning designs or support the sharing of educational ideas. Nevertheless, these repositories and portals do not incorporate tools to enable the design co-creation.

LdShake is a web tool whose novelty falls on providing educators with a set of technological features for team formation, the storage and retrieval of learning designs shared and generated by teams, enabling and promoting interactions in the process of co-creating those designs. The combination of these features seems to provide a relevant framework for satisfying the requirements of on-line teambased work in the context of learning design. LdShake does not offer a new learning design editor, instead, it integrates existing learning design web editors (e.g., WebCollage, eXeLearning, Rich Text editor) visualizing them in the same interaction context while also adopting the LdShake team formation, storage and retrieval and co-editing facilitation technological features (Hernández-Leo et al., 2011a). Moreover, LdShake can be customized to the needs of specific learning situations (e.g., templates for designs based on specific didactic methods, such as PBL). A first version of LdShake was presented and evaluated in a use case and control experiment in (Hernández-Leo et al., 2011b), where the tool was compared with existing systems used by educators to support networked team collaboration (Moodle, Google Docs, e-mail...). The results indicated that the integrated support provided by LdShake in the context of a single platform devoted to learning design facilitated a more effective approach. However, these evaluations did not value the usefulness and usability of the LdShake technological features in real contexts.

This paper introduces and evaluates a second version of the system improved in terms of robustness, front-end layout and usability, and details its technological features for the support of teambased learning design. The evaluation is focused on understanding to what extent and in which way the LdShake technological features are useful to support the team-based work requirements. The evaluation is conducted in two contexts; the first is genuinely focused on learning design while the second is devoted to devising research ideas. Both contexts focus on learning and innovation aims. The first context is an LdShake authentic situation where participants were asked to ideate learning designs in collaboration with their peers. The second context represents a more synthetic situation where LdShake supported the collaboration of a university research group in the sharing and co-definition of research ideas. Though this second case is less significant for the purposes of LdShake, it provides interesting complementary results about the usefulness and usability of specific LdShake features to support networked teams. These results do not only provide insights referring to LdShake but they also offer lessons learnt regarding technological means and affordances that can be considered to support other types of networked teams.

Section 2 describes the LdShake technological features. Then, section 3 explains the two contexts in which LdShake has been used and presents the evaluation results obtained in each context. After a discussion of the complementary findings derived from the two contexts, section 4 concludes the paper and points out future work. 


\section{LdShake technological features in support of networked teams}

LdShake is a social web tool for the collective edition and sharing of Learning design Solutions (LdS). Its name stands for "Learning design Solutions - Sharing and K(c)o-edition". "Shake" serves as a metaphor which links the different actions that users, referred to as LdShakers, can perform with the tool. All these actions are briefly stated in the site homepage and in the new users' welcome page (see Fig. 1).

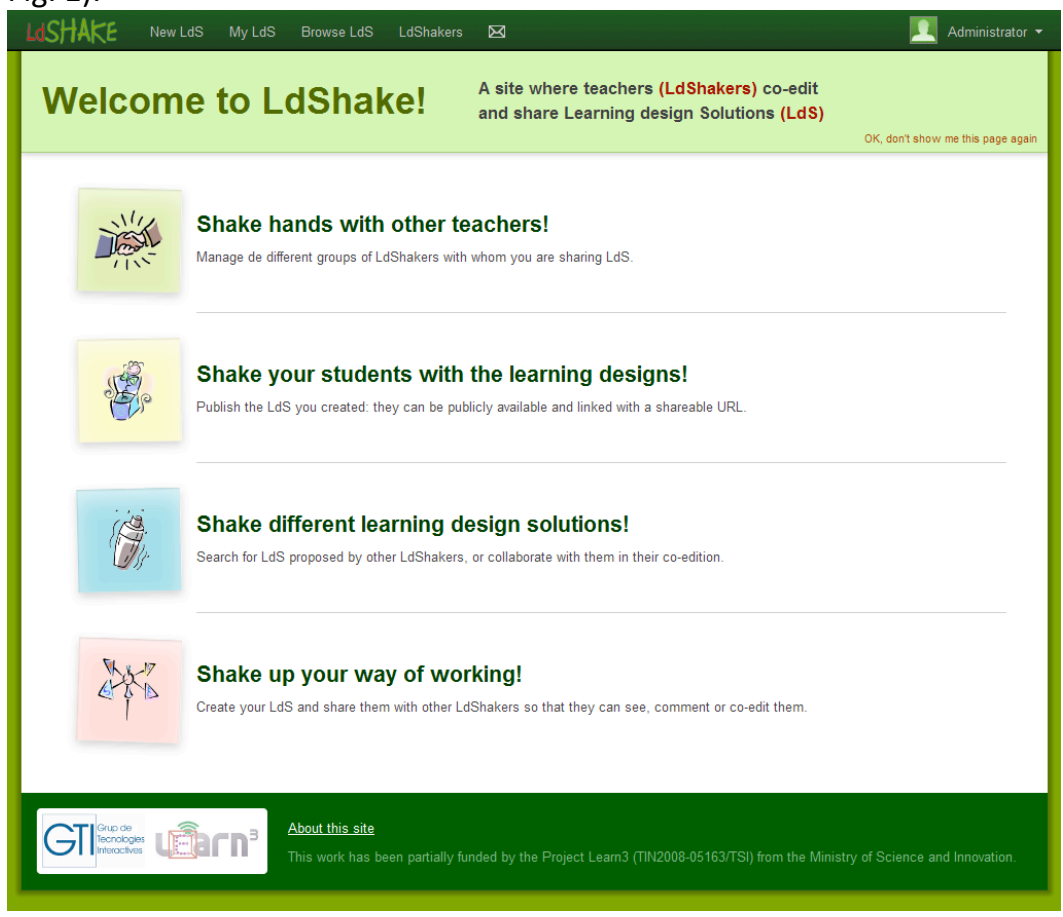

Fig. 1. LdShake welcome page guiding the user through the top bar options with dynamic labels and buttons (http://Idshake.upf.edu)

Table 1 collects the LdShake technological features for the support of team-based learning design. The features are organized into three main categories of requirements, namely: team formation, storage and retrieval of designs, and enabling and promoting interactions between users (educators and eventually other stakeholders, such as educational researchers, designers, etc.) in the process of cocreating the designs.

Table 1

LdShake technological features for supporting learning design team-based work requirements

\begin{tabular}{|c|c|}
\hline Requirements & Technological features \\
\hline \multirow{4}{*}{ Team formation } & $\begin{array}{l}\text { (a) Through shared designs according to tree different types of user roles regarding an LdS: } \\
\text { starter, editor and viewer-commenter }\end{array}$ \\
\hline & (b) Creation of private named collections or groups of users \\
\hline & (c) Visualization of the users (LdShakers) registered in the system \\
\hline & (d) Requests for edition permissions to the LdS owner through private messaging \\
\hline \multirow{4}{*}{$\begin{array}{l}\text { Storage and retrieval of (shared) } \\
\text { designs }\end{array}$} & (e) LdS tagging, three different types of tags: discipline, pedagogical approach and free tags \\
\hline & (f) Different types of LdS listings (or menus): by user's rights (editing and viewing) \\
\hline & (g) Different types of LdS listings: by user starting an LdS \\
\hline & (h) Publishing LdS outside the platform \\
\hline \multirow{3}{*}{$\begin{array}{l}\text { Enabling and promoting } \\
\text { interactions in the process of co- } \\
\text { creating designs }\end{array}$} & $\begin{array}{l}\text { (i) Wiki-style editing or reading access to a design according to the role the user has for this } \\
\text { design }\end{array}$ \\
\hline & (j) LdS revision graphs, co-editors and history browsing \\
\hline & (k) Comments to LdS (notified via email to the starter) \\
\hline
\end{tabular}




\subsection{Technological features supporting team formation}

As summarized in Table 1, LdShake supports team formation by managing different user roles associated to shared designs (a), the possibility of pre-defining groups (b), facilitating the visualization of the members registered in the system (c) and a mechanism to request access to designs (d). The way in which these features are provided in LdShake is unique because LdShake has been conceived for supporting a single relatively small community of educators (e.g., educational institution, transversal initiatives across institutions). In fact, the tool is designed to be easily replicated in a different instance of the platform and customizable according to the needs of specific communities of educators. This association of LdShake with a single small-scale community of educators has led to design their features regarding user socialization and team formation in a different fashion if compared to mainstream social web applications (Berlanga et al., 2007). In the majority of social web applications and networks, a user needs to explicitly establish a relationship with another user to enable richer interactions between them (e.g. "subscribe", "follow" or "add as friend" actions). In contrast, in LdShake it is assumed that the members of a community of educators have a pre-existing relationship. These connections are preestablished between all the LdShakers. In this way new users can see existing users, can comment on the existing designs that are set as public, as well as send private messages to everyone in the community.

Teamwork between LdShakers takes place in the context of a design, which acts as the "social object" of the platform (Knorr-Cetina, 1997). The teams are formed by granting read or write access to other LdShakers. It is the creator of a design who decides who will be able to edit it and who will be only able to view and comment it (feature (a) in Table 1). In LdShake the role of the creator (the user who actually starts a design) is called starter, and has a set of special rights over this design. The starter can manage the access permissions of a design; she is also the only one who has the ability to disseminate a design outside the platform by publishing it through a public URL. Moving designs to the trash is the other special right whose usage is restricted to the starter. Trashed designs are only visible to their starter, and only the starter can recover them. This approach is a trade-off solution since as designs in the platform can be product of teamwork and their deletion can cause conflict. LdShakers who have been granted write access to a design can see the list of colleagues the design is shared with, whereas LdShakers with viewing rights will not be able to know who can edit the design. However, these users will be able to comment the designs, to navigate through their revision history, to export any of their documents as PDF files and to see and use their public URL (if published). By default, the designs created in LdShake are shared with viewing access rights between all the LdShakers (all the logged in users), and the only user who can edit the access right is its starter. The aim of this default access policy is to foster the sharing of designs, by enabling their discoverability for all the members of the community. Table 2 shows which permissions are associated to each role of the LdShakers for a specific design.

Table 2

List of permissions over a design (an LdS) associated with each user role in the platform

\begin{tabular}{|l|c|c|c|}
\cline { 2 - 4 } \multicolumn{1}{c|}{} & Starter & Editor & Viewer \\
\hline View LdS contents & $\mathrm{X}$ & $\mathrm{X}$ & $\mathrm{X}$ \\
\hline Comment LdS & $\mathrm{X}$ & $\mathrm{X}$ & $\mathrm{X}$ \\
\hline View LdS revision history & $\mathrm{X}$ & $\mathrm{X}$ & $\mathrm{X}$ \\
\hline Export documents as PDF & $\mathrm{X}$ & $\mathrm{X}$ & $\mathrm{X}$ \\
\hline View exported LdS URL & $\mathrm{X}$ & $\mathrm{X}$ & $\mathrm{X}$ \\
\hline Edit LdS contents & $\mathrm{X}$ & $\mathrm{X}$ & \\
\hline See LdS access rights & $\mathrm{X}$ & $\mathrm{X}$ & \\
\hline Publish LdS documents & $\mathrm{X}$ & & \\
\hline Assign LdS access rights & $\mathrm{X}$ & & \\
\hline Move LdS to trash can & $\mathrm{X}$ & & \\
\hline
\end{tabular}

Regarding the user interface, working groups for a design are set via a dialog box which allows setting viewer and editor rights. LdShakers can be added individually to the working team of a design by typing their name in the form text boxes, but the platform also offers the possibility to create named collections of users (b). These collections are created in the LdShakers section of the website, which visualizes all the users registered in the system (c). Creating and naming collections of users (especially when different access rights will be assigned to them) can be a very personal task, therefore these collections are private, meaning that only the creator will be able to see them. Having these named 
groups, a user can add all their members to any learning design by typing the group names in the form. When adding a group, the design will not hold a reference to this group, but will store references to all its members instead. The visual feedback of the sharing form when adding a collection reinforces this behaviour (see Fig. 2). Consequently, changes to a user collection performed at a specific point of time do not affect the sharing options of the previously created designs where this collection was used. This means that it is more difficult for the users to lose control of the sharing options of their designs, and that it is easy for them to handle situations such as wanting to include everybody from group $X$ except the users $A$ and $B$.

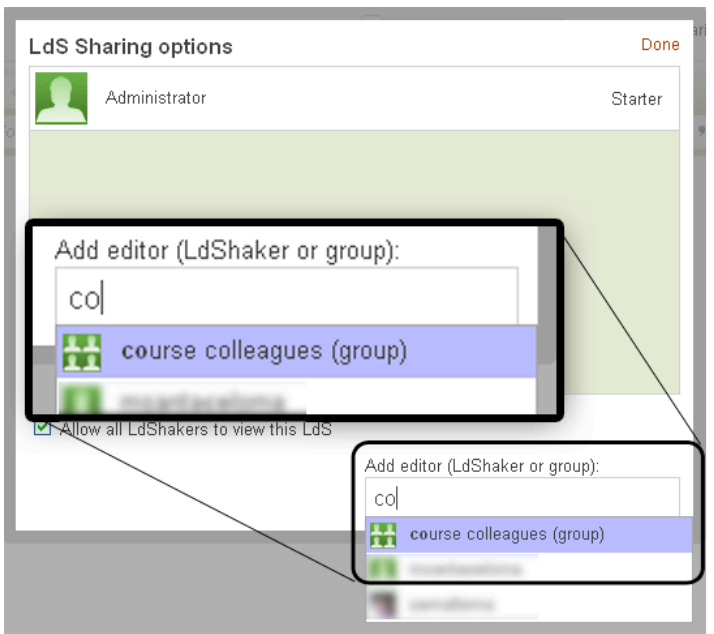

(a)

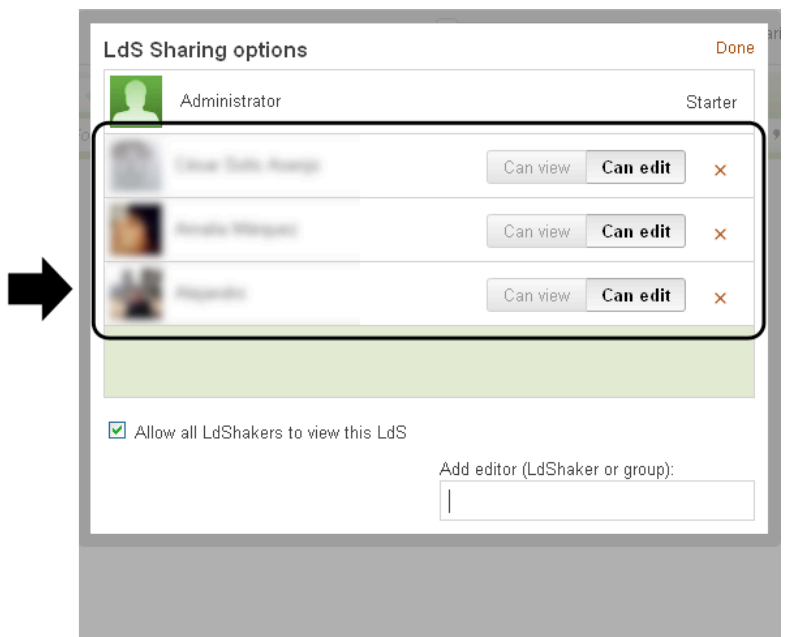

(b)

Fig. 2. (a) LdS sharing options dialog box, where a name of a user collection is being typed in order to add its members as editors (b) The members of the "course colleagues" collection are added to the LdS as editors, but no further references to the group name are shown

LdShake also features a private message service (d). If users with reading access to certain LdS wish to participate in their editing, they can use this service and send a direct message to the LdS starter to request her to be included in its edit team.

\subsection{Technological features supporting storage and retrieval of designs}

In order to make design storage and retrieval easy and natural, and given that LdShake is intended to serve both as a co-editing tool and as repository for shared designs, two types of LdS listings (f) were designed for these two different purposes (see Fig. 3). For the co-editing part, the platform offers a section called $M y L d S$, which displays the designs the user is the starter of and the ones she has writing access to. The designs are sorted chronologically by the time of latest revision, and unseen or modified designs are visually highlighted. In the "My LdS" section, designs can be filtered by two criteria: only the LdS that the user has started ("Created by me") and only the ones that she has writing access to (without her being the starter, "Shared with me"). By default, the union of these two criteria is shown to the user.

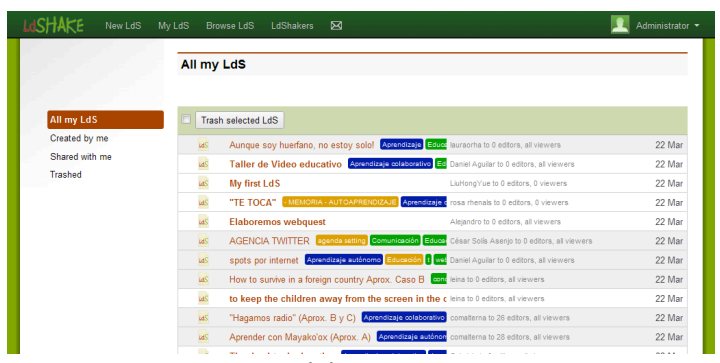

(a)

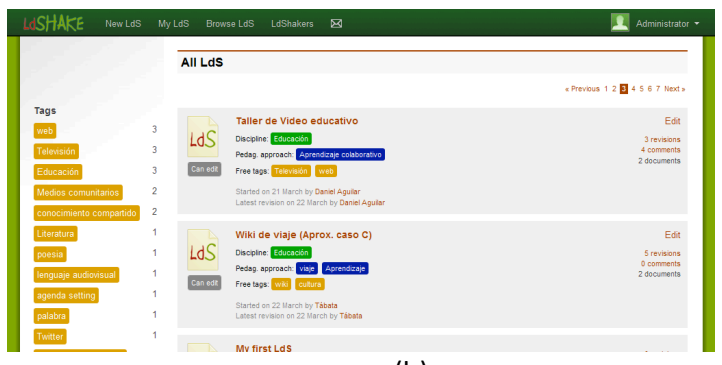

(b)

Fig. 3. (a) List of LdS in the My LdS Section: a large number of designs can be shown in a page (b) Visualization of the learning designs in the Browse LdS section: more screen space is devoted to describe each LdS of the list

For its usage as a repository or explorer of shared designs, the platform offers a section called 
Browse LdS, which lists all the designs the user can read and comment. In this section more information about the designs is shown to the user in order to give her a better idea about its contents, purpose and state. This information includes the tags of the designs (e). Filtering the designs by tag is supported via a sidebar listing them in order of frequency. Three types of tags can be associated to an LdS: discipline (e.g. mathematics), pedagogical approach (e.g. PBL) and free tags. In order to avoid dispersion of the tags, the tagging dialog box has an autosuggest feature which presents existing tags matching the typed text. Moreover, another interesting query a user may perform regarding designs is viewing all the LdS started by other colleagues (g). The profile page of an LdShaker displays the designs that he has started and which the user has read access to.

LdShake also offers publishing designs outside the platform $(h)$ with a short URL. This URL will be accessible to any visitor, even the ones who are not logged into the system. Once a design is published, latter revisions do not get automatically published, changes need to be re-published explicitly instead. With this functionality, draft modifications can be performed safely in LdShake even when designs are published and their public link has been disseminated (to students, for example), as these changes will not appear in the published version. Learning designs can also be saved as PDF documents for their portability to other contexts and devices, or for printing.

\subsection{Technological features enabling and promoting interactions for the co-creation designs}

LdShake does not propose a new learning design editor. Instead, it integrates existing learning design web editors, such as WebCollage, eXeLearning or a Rich Text editor - as shown in (Hernández-Leo et al., 2011a). The support for co-editing designs (with all of their integrated editors) is addressed following a wiki read/write approach (Cifuentes, Sharp, Bulu, Benz \& Stough, 2009) that is activated to the user for each design according to the role of user for that design (i). This approach is interesting because it is independent of the integrated editor, yet it enables co-creation of designs. As motivated in the introduction, educational innovation initiatives requiring the inter- or intra-institutional collaboration of educators and other educational stakeholders would benefit from this co-editing support. The provision of several learning design editors also offers to the users authoring tool flexibility in the context of the same collaboration platform. As Fig. 4 shows for the case of the rich text editor (it is similar in the case of the other editors integrated), the editors are visualized within the LdShake interaction context and adopt all of the LdShake technological features. The editor area automatically expands to occupy all the available screen space. There is a button to save changes without closing the form, so users can periodically save their work. Semaphores have been implemented in order to prevent a user "stepping on" changes that another user has made on a design if the two of them were editing it at the same time.

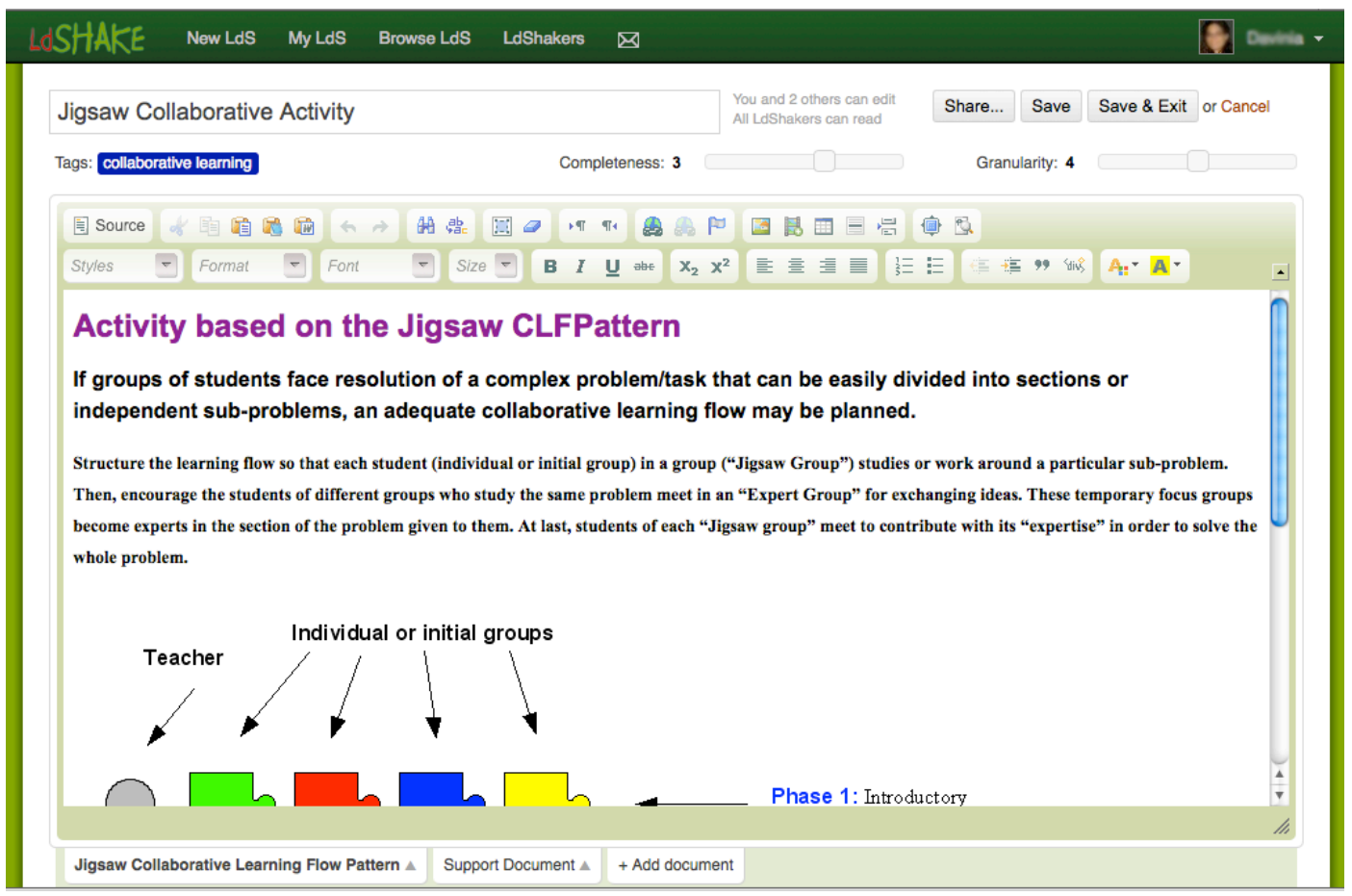


Fig. 4. Editing a design in a rich text editor, adopting the LdShake wiki-style support for co-editing and the sharing and tagging features.

To support and promote co-editing, LdShake provides a revision history that tracks editions to designs using a graphical representation (j). Revisions are listed vertically and associated to the user who made them and the date. Colour codes indicate the kind of changes (creation of a sub-document, modification or removal). When clicking to any revision, the design is displayed and changes between the current revision and the previous one can be shown and highlighted (see Fig. 5).

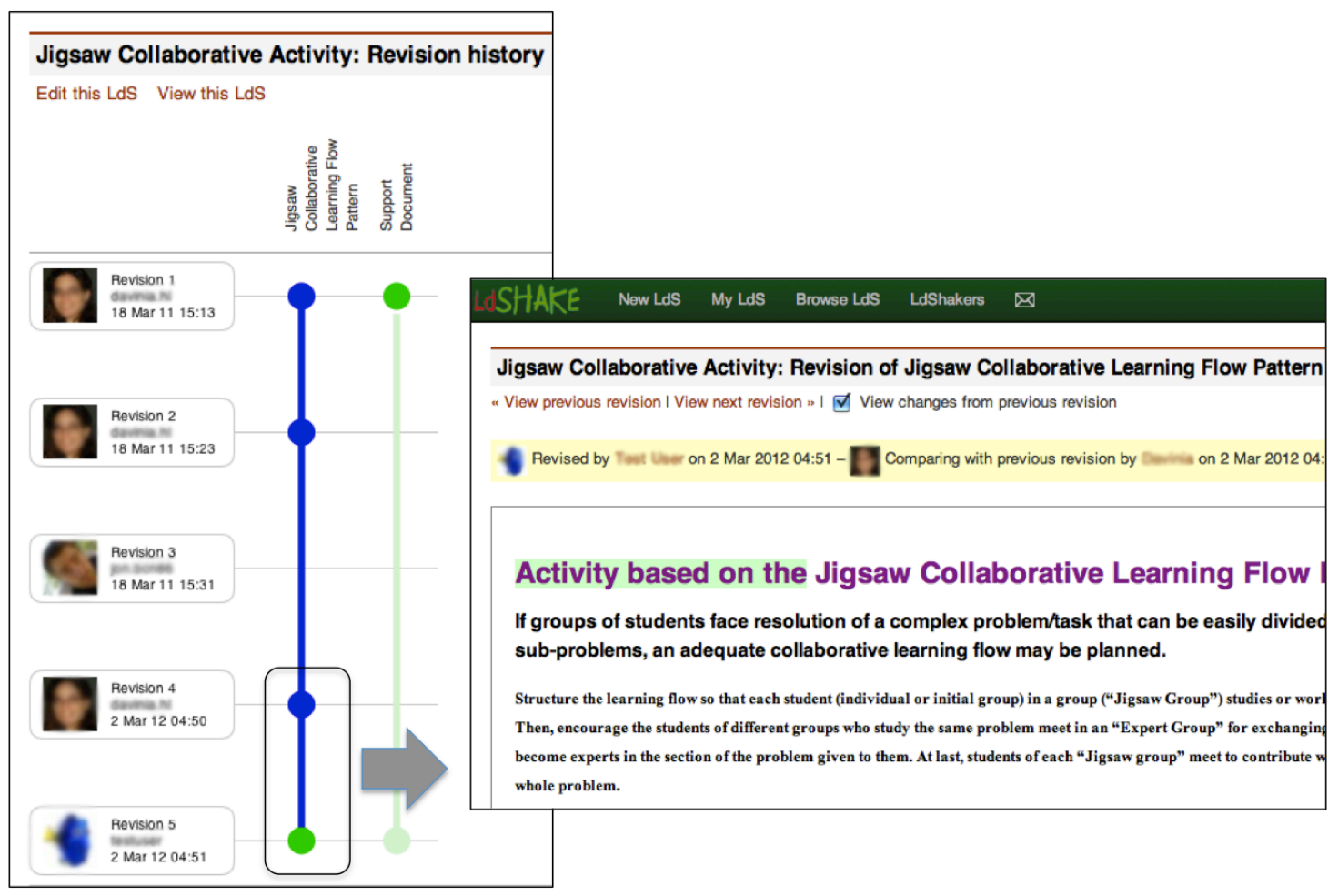

Fig. 5. LdS revision tree showing each revision's author and date (left box) and revision of two specific revisions of a document, with changes highlighted in red and green (right box).

Finally, any user who has viewing access to a design can add comments (Neuwirth, Kaufer, Chandhok, \& Morris, 1990) to establish design conversations, which can eventually lead to changes in the designs. These comments are publicly displayed (to users who can view the designs), and notified to the starter via email $(\mathrm{k})$.

\section{LdShake technological features evaluation in two contexts}

To analyze the utility and usability of the LdShake technological features for the support of networked teams, LdShake has been applied to two contexts of use. The first context is genuinely focused on learning design while the second is devoted to devising research ideas. Though the results provided by the first context are more relevant to the purposes of LdShake, the second context can provide complementary results about affordances of LdShake for other contexts and distinct user behaviours that can depend on the characteristics of each context. In particular, the research questions under evaluation are: To what extent and in which way do the LdShake technological features $(a, b, c, d)$ support team formation? To what extent, and in which way, do LdShake technological features (e, f, g, h) support storage and retrieval of (shared) designs? To what extent and in which way do the LdShake technological features $(i, j, k)$ enable and promote interactions in the process of co-creating designs? Do the user behaviours when interacting with LdShake vary depending on the context of use? The answers to these questions are expected to contribute towards an improved understanding of how to support networked teams. 


\subsection{Description of the learning design and research evaluation contexts}

The first context is framed in a Master degree where a total of 27 participants with educational and media communication backgrounds were asked to create one or two learning designs using LdShake. The designs were explicitly requested to be innovative. Participants were encouraged to share their designs with some of their colleagues so that they could collaborate towards the (co-)creation of more creative and richer designs. They had a total of 10 days to complete this activity virtually (on-line and from the distance), without any previous training in LdShake. According to a pre-questionnaire distributed to the participants, all of them had a large (53\%), quite large (33\%) or fair (13\%) experience in teamwork. A $46 \%$ of the users had a large (13\%), quite large (13\%) or fair $(20 \%)$ experience in teamwork supported by on-line tools. When asked about what these tools are, the answers are varied and different depending on the person; including wikis, blogs, social networks, e-mail, chats, Google Docs and forums. Concerning the use of social networks, the $70 \%$ said to use Facebook and a few of them confirmed to be users of Linkedln, Twitter or Xing.

The second context corresponds to a research team on interactive technologies composed of 20 members ( 3 senior researchers, 7 junior researchers, 10 research assistants) using LdShake in the codevising of research ideas. The $75 \%$ of them attended a short presentation about the tool and were invited to use it as long as they wanted to. The data analysed in this paper correspond to the usage of LdShake during a month. Participants were requested to complete a similar pre-questionnaire as in the previous context. In this case also all of the participants had a large (25\%), quite large (63\%) or fair (13\%) experience in teamwork. A larger percentage, $87 \%$, had a large (13\%), quite large (63\%) or fair (12\%) experience in teamwork supported by on-line tools. The tools used are more varied than in the previous case and differ depending on the person; including SVN, wikis, Google Docs, Dropbox, e-mail, Moodle, Trac and forums. Regarding the use of social networks, the $70 \%$ said to use Facebook and a few of them confirmed to be users of Myspace, Flickr or Twitter.

\subsection{Evaluation methodology}

To evaluate the use of LdShake in each context it is necessary to consider several factors such as the contextual issues, the characteristics of the participants, the inherent complexity of the human processes and the impact of the system features. Therefore, the evaluation is conducted following a mixed method that combines the use of quantitative and qualitative data (Cairns \& Cox, 2008; Morse, 2003). The data is triangulated so that quantitative data enable the identification of trends and the qualitative opinions facilitate the further understanding of those trends and the identification of emerging issues (Guba, 1981).

The quantitative data were gathered in both cases using two sources, namely, ratings in a subjective post-questionnaire about the features of LdShake, completed by the participants after the experience, and objective logs registering users' actions, automatically recorded by the system. The ratings included items that explicitly asked the users about to what extent the technological features were useful. Examples of items include, "to what extent creating pre-defined groups was useful for you", "to what extent you find appropriate the policies for user roles and shared designs", "to what extent you find useful being able to visualize the history of editions to a design", etc. Users could rate each item in a scale of "very useful", "quite useful", "not very useful", "not useful at all", or "I haven't used this feature". The logs provided information about the use of the tool and the users' behaviours when using the tool. The data collected in the logs included the number of designs created and shared, the number of visits and time-on-site (per visit, per user), and the frequency of use of the technological features. The qualitative data were collected though comments in open questions included in the post-questionnaire. In these open questions participants were asked to explain their ratings and to point out the positive and negative aspects of LdShake as a whole. Next subsections present the results obtained from the analysis of these data ${ }^{1}$.

\subsection{Results "Learning design" context}

The participants in this context created a total of 41 designs using the rich text editor integrated in LdShake. During the 10 days they visited the site 200 times, accessing an average of 621 pages per day

\footnotetext{
${ }^{1}$ An extended analysis of the ratings and comments is available in an on-line appendix at $\mathrm{http}: / /$ ldshake.upf.edu/gti/v/ban
} 
and 31 pages per visit. The time-on-site for each visit was rather varied, though it is possible to say that most of the visits were either of 5-15 minutes or beyond 1 hour. Moreover, there was also a significant number of times in which LdShake was used during 15-30 or 30-60 minutes. These data show a trend suggesting that participants worked using LdShake on the elaboration of their learning designs or on collaborating in the editing or commenting of LdS created by other colleagues. Besides, in some occasions they logged in the system to briefly check or comment on some issue about the designs. Table 3 summarizes the evaluation results obtained in this context. They are organized in line with the teambased work requirements to which LdShake provide technological features as presented in Section 2 and Table 1.

Table 3

Learning design context: summary of results

\begin{tabular}{|c|c|}
\hline Requirements & Results \\
\hline \multirow{5}{*}{ Team formation } & $\begin{array}{l}\text { Being able to see the list of individuals registered in the system and their profiles was perceived as very } \\
\text { useful, and seemed to be an important precondition for the formation of groups (c). }\end{array}$ \\
\hline & The explicit definition of private named groups was limitedly used, but rated as largely useful (b). \\
\hline & $\begin{array}{l}\text { Almost the } 90 \% \text { of the participants found it largely useful that LdS creators are the ones who form the } \\
\text { groups of users associated to the designs and that it is possible to distinguish between "edit" and "access" } \\
\text { rights (a). }\end{array}$ \\
\hline & $\begin{array}{l}\text { While many LdS had associated a team of editors (LdShakers with editing rights), most of them are shared } \\
\text { with all logged users with reading rights (a). }\end{array}$ \\
\hline & $\begin{array}{l}\text { Though the use of private messages to request access rights to LdS was limited, the participants rated } \\
\text { positively this facility and valued its support to send direct private observations to authors (d). }\end{array}$ \\
\hline \multirow[b]{2}{*}{$\begin{array}{l}\text { Storage and } \\
\text { retrieval of } \\
\text { (shared) designs }\end{array}$} & $\begin{array}{l}\text { The main sections of "My LdS" and "Browse LdS" were often used, and in some occasions LdShakers } \\
\text { decided to use the filters (of "My LdS") "Created by me" and "Shared with me" (f). }\end{array}$ \\
\hline & $\begin{array}{l}\text { Tags were useful to classify the designs and connect them. However, its implementation showed to have } \\
\text { usability problems, which hindered its broad use (e). } \\
\text { Browsing LdS by LdShaker was preferred (g). } \\
\text { Users did not have the need of publishing designs outside the platform in this context }(\mathrm{h}) \text {. }\end{array}$ \\
\hline \multirow{3}{*}{$\begin{array}{l}\text { Enabling and } \\
\text { promoting } \\
\text { interactions in } \\
\text { the process of co- } \\
\text { creating designs }\end{array}$} & $\begin{array}{l}94 \% \text { of the participants agreed that monitoring the joint creation of LdS using the LdShake "history" facility } \\
\text { was largely useful (j). It was used in a significant number of LdS to reflect on the development stages of the } \\
\text { educational designs performed by the team members }(i, j) \text {. }\end{array}$ \\
\hline & $\begin{array}{l}\text { A significant involvement of team members (both belonging to the editing and reading groups) was } \\
\text { achieved via the commenting facility, which was especially used and valued by the participants (k). }\end{array}$ \\
\hline & $\begin{array}{l}\text { LdShake facilitates flexible team-based learning design thanks to the sharing of design ideas (global), the } \\
\text { opinions and comments of other participants (k), and the direct contributions of team members (i). } \\
\text { Some participants seemed to think that the control of the LdS should remain in the creators (related to a). } \\
\text { Proposals for extension include integrating a chat facility and extending the editing formats. }\end{array}$ \\
\hline
\end{tabular}

A key feature to support the processes of team formation appeared to be the visualization of the users participating in that LdShake instance or community (technological feature c in Table 1). The participants rated this feature as very $(44 \%)$ or quite $(56 \%)$ useful and used it considerably (the list of LdShakers was seen a total of 551 times, $8.9 \%$ of the pages viewed). Participants indicated that this facility enabled them to identify colleagues sharing their affinities. They provided comments such as "I can see colleagues using the system and create groups to share our proposals" or "Thanks to the visualization of the LdShakers list I can define my teams according to affinities and to the thematic line of everyone". The explicit definition of private, named groups (b) was, however, limitedly used (3 groups). Since almost all of the participants said that they found this feature (very) useful (94\%), the short time-scale was probably the reason of so few named groups in which LdShake was used.

The data show that the participants found largely appropriate that the starters of the designs are who decide with whom to share the designs (a), with ratings of "very appropriate" (39\%) and "appropriate" (50\%) and comments like, "The creator of a design should have the freedom to decide if others can edit the design or only see its content". Additionally, they felt the differentiation between editing and reading access groups assigned to the same design (still feature a) was useful and opportune ( $50 \%$ found it very useful and $39 \%$ quite useful). One participant claimed, "Sometimes there are people sharing your affinities and you would like that they can edit your designs as part of your team. In addition, your interest may be that other people can look at them and comment, contributing to enrich the ideas but without changing the content". The participants made extensive use of the sharing facility employing the different access rights. Concretely, the $61 \%$ of the designs were shared with a group of users with editing rights, whereas only the $4.9 \%$ were fully private. Participants valued positively the private message service (d) as a feature that enables, among other things, to request access to designs (found as useful or very useful for this purpose by the $94 \%$ of the participants). Nevertheless, its usage 
was very limited (5 messages).

The organization provided by LdShake to store and retrieve the designs seemed to largely suit the users' goals. $94 \%$ of the participants rated this organization as "useful" or "very useful", and confirm their ratings with opinions like, "The menus establish an order and provide easy search". The main sections of "My LdS" and "Browse LdS" (f) were often used ("My LdS" represented a 10.5\% of the pages viewed and "Browse LdS" a 17\%), and in some occasions LdShakers decided to use the filters "Created by me" and "Shared with me" (1.1\% and $9.9 \%$ of the pages viewed respectively). It is noteworthy that participants used the "Browse LdS" section significantly more often than "My LdS". Many participants (83\%) indicated that tags (e) were useful to classify the designs and to connect them with related designs. However, their use was not significant (browsing LdS using the tags was performed 96 times, $1.5 \%$ of the pages visited), probably because tag visualization could be improved as pointed out by the participants. On the other hand, it is interesting that designs were often accessed through the LdShakers menu (g) (8.9\% of the pages viewed), meaning that participants were interested in seeing LdS created by particular colleagues.

Regarding the support for interaction in the co-creation of designs, the history feature (j) proved to be successful both in the perception of usefulness by the users (perceived as "very useful" or "useful" by a $94 \%$ of the participants) and the actual use. LdShakers have checked the history of $58.5 \%$ of the designs at least once. The history of each design has been checked an average of 4.3 times. Participants highlighted in their opinions the important role of this facility to follow co-creation process of the designs and so the starter of the design can keep the control. In addition to the direct edits (i), a significant involvement of team members (both belonging to the editing and reading groups) was achieved via the commenting facility (k), which was especially used (61\% of the designs had comments average of 2.5 comments per LdS) and valued by the participants (61\% valuing it as "very useful", $33 \%$ as "useful"). According to their remarks, some of the comments made by other users were considered to modify the designs, "... the comments provide insight to what is being written. Many times the changes performed in the document are generated by the contributions expressed in the comments".

The $89 \%$ of the participants agreed that LdShake support to a large $(28 \%)$ or to some extent $(61 \%)$ collaboration between educators enables them to devise educational designs that can eventually be more creative, innovative or rich. This support is comprised mainly of the following features: the sharing of design ideas and experiences (global), the comments provided by other participants $(\mathrm{k})$ and the direct contributions in the LdS by editing team members (i). Comments pointing out these aspects include: "The designs can be more creative or rich thanks to the interchange of experiences" or "Thanks to others' opinions or their editions, the designs are enriched". On the other hand, there are also some opinions that show the eventual resistance that teachers may have using tools such as LdShake, "The designs are more creative because of the contributions from the peers, but I think that the creator should have the control". Finally, participants also proposed to extend the system with a chat facility and to give support to edit a richer range of authoring formats (e.g., conceptual maps).

\subsection{Results "Research team" context}

The participants in the second contexts created a total of 38 designs using the richt text editor. During the month they were using LdShake they visited the site an average of 12 visits per day, accessing an average of 120 pages per day and 10 per visit. The time-on-site for each visit was rather different from the situation in the other context. In this case most of the visits were of shorter durations. Still, there are more thank 40 visits lasting more than an hour and more than 60 during either 15-30 or 30-60 minutes. These data suggest that some participants worked using LdShake on elaborated research ideas and the like (e.g., proposals for research seminars) but most of the times the participants logged in the system to briefly check or comment designs documented in LdShake. Table 4 summarizes the results obtained about the use of the LdShake technological features in this context.

Table 4

Research context: summary of results

\begin{tabular}{|l|l|}
\hline Requirements & Results \\
\hline \multirow{3}{*}{ Team formation } & $\begin{array}{l}\text { Being able to see the list of individuals registered in the system was perceived as very useful, to both } \\
\text { improve interpersonal trust and group awareness (c). } \\
\text { The explicit definition of groups was fairly used when compared to the other context, probably } \\
\text { because named groups were perceived as more reusable in this context (b). }\end{array}$ \\
\cline { 2 - 2 } & All of the users found largely useful that creators select the users who can access their designs and \\
\hline
\end{tabular}




\begin{tabular}{|c|c|}
\hline & $\begin{array}{l}\text { that it is possible to distinguish between "edit" and "view" rights (a). } \\
\text { While many LdS had associated a team of editors, most of them are shared with all logged users with } \\
\text { reading rights (a). }\end{array}$ \\
\hline & $\begin{array}{l}\text { The feature of sending direct privates messages to users was perceived as useful in general, used in } \\
\text { more occasions than in the other context, but still limitedly (d). }\end{array}$ \\
\hline \multirow{2}{*}{$\begin{array}{l}\text { Storage and retrieval of } \\
\text { (shared) designs }\end{array}$} & $\begin{array}{l}\text { The main sections of "my LdS" and "Browse LdS" were often used, and in some occasions LdShakers } \\
\text { decided to use the submenus (of "My LdS") "Created by me" and "Shared with me". Contrary to the } \\
\text { other case, the "Browse LdS" section was used less than "My LdS" (f). }\end{array}$ \\
\hline & $\begin{array}{l}\text { Tags were perceived as useful to flexibly categorize LdS by topics and identify the emerging areas of } \\
\text { work of the community using the LdShake instance (e). However, tags were almost not used to } \\
\text { search LdS. Browsing LdS by LdShakers seemed to be preferred (g). } \\
\text { URLs to published designs in LdShake were largely used in e-mail communications (h) }\end{array}$ \\
\hline \multirow{3}{*}{$\begin{array}{l}\text { Enabling and promoting } \\
\text { interactions in the } \\
\text { process of co-creating } \\
\text { designs }\end{array}$} & $\begin{array}{l}91 \% \text { of the users agreed that monitoring the joint creation of LdS using the LdShake "history" facility } \\
\text { was largely useful (j). It was used in a significant number of designs at least once to see who has } \\
\text { contributed what to the editing of the design (i) in a time ordered visualization. }\end{array}$ \\
\hline & $\begin{array}{l}\text { The possibility of adding comments to LdS was perceived as very useful (k). However, in this case this } \\
\text { feature has been used fewer times than in the previous context. }\end{array}$ \\
\hline & $\begin{array}{l}\text { LdShake provides an intuitive knowledge management solution for team-based research and enables } \\
\text { co-editing (global). Proposals for extension are related to awareness features, including a notification } \\
\text { system to inform about new designs and changes in exiting designs. }\end{array}$ \\
\hline
\end{tabular}

As in the previous context, being able to see the list of users registered in the system (c) appeared as a relevant feature supporting team formation. The majority of the participants rated this feature as very $(73 \%)$ or quite $(18 \%)$ useful and used it considerably (access to the list of LdShakers represents a $4.6 \%$ of the pages viewed). In their qualitative comments the members of the research team indicated that this technological feature is important to foster interpersonal trust among the LdShakers in the system and enabled them to explore and be aware of the work their colleagues were carrying out. The explicit definition of private named groups (b) was fairly used when compared to the previous context (13 groups), probably because the time-scale of this context was longer and the predefined groups were perceived as more reusable. $64 \%$ of the participants rated this feature as "very useful" and $27 \%$ as "useful". They commented, "It's very useful to be able to pre-define sub-groups within LdShake since many of us work in small working groups and this way I can more quickly share with them the LdS", "I like that the support for the definition of groups is personal, so that each of us can have their own groups and understand its logic..." Yet, some users took advantage of the implicit formation of groups by the sharing of the designs, as it was broadly done in the previous context; "I haven't had the need of creating a new group, I think that I have preferred binding the persons directly to the designs".

This second context confirms that users find appropriate that the starters of designs assign their access rights (91\% rated it as "very appropriate", 9\% as "appropriate") and form two types of groups (editing and reading) associated to those LdS ( $82 \%$ found it "very useful" and 18\% "useful"). Again, the participants made extensive use of the sharing facility employing the different access rights (a). Concretely, the $74 \%$ of the designs had assigned editing teams and only the $5.3 \%$ were fully private. The feature of sending direct privates messages (d) to users is perceived as useful in general (82\%) and it is used more often than in the previous case (26 messages), though still limitedly. Users did see the need of the eventual request of editing access to designs in the case that interaction opportunities are identified, "Reading a design may trigger options for collaboration, so it's necessary to have a facility to request access to edit an LdS. If the reader identifies this option for interaction, he needs to be able to ask the creator", but it is not clear to what extent the private messages were used for this purpose. In particular, users' comments indicated that the message service was useful to privately discuss research issues, "It's useful to have a private messaging service inside the platform to exchange comments regarding work made in LdShake. In this way, users don't need to leave the context when reading and writing these messages".

The data collected show that the organization provided by LdShake to store and retrieve the designs seemed to largely suit participants' goals. The organization in different types of listings (f) was rated as (very) "useful" by the $82 \%$ of the participants, with opinions, "I can distinguish easily those designs I can read and those I can edit. Browsing LdS is very helpful to explore content created by other users". The main sections of "My LdS" and "Browse LdS" were often used ("My LdS" accesses represent a 16\% of the pages viewed; "Browse LdS" a 6.2\%), and in few occasions LdShakers decided to use the filters "Created by me" and "Shared with me" ( $0.85 \%$ and $0.5 \%$ of the views respectively). Interestingly, contrary to the previous context, participants used the "Browse LdS" menu significantly fewer times than "My LdS". Participants also indicated in their comments that they tended to explore mostly those designs they could edit. Tags (e) were perceived as very useful (82\%) or useful (18\%) to flexibly categorize designs by 
topics and identify the emerging areas of work of the community using the LdShake instance; "The tags are great to find the LdS and navigate by topic... It also enables identifying what types of things are being tackled by your colleagues". However, tags were almost not used to search designs (16 times).

According to their comments, a better organization of tags and complementary search tools would be helpful. As in the other context, browsing LdS by LdShakers $(\mathrm{g})$ was preferred in many cases $(2.7 \%$ of the views). As one participant claimed, "I find it very useful to be able to explore directly the designs created by a specific LdShaker that you would like to follow". Furthermore, it is important to mention that since each LdS has a unique URL identifying the design within the system, participants did also refer to those designs directly (mainly in e-mail communications) and accessed them directly through the URL (h).

Regarding the enabling interactions in the co-editing process, most users valued highly the usefulness of the history feature (j) to support the co-creation of designs (rated as very useful by $82 \%$, as useful by $9 \%$ ). Its use was significant, though slightly lower than in the previous context. The graphical representation of the changes in history was checked in $42.1 \%$ of the designs. This feature provided confidence to both the starters, who could see the contributions of the team and decide if they wanted to undo edits (i), and to the editors, who felt motivated to contribute because their edits would be socially recognized. The graphical visualization of the history was greatly appreciated by the users, "The history enables us to see exactly which has been the contribution of the different editors, providing a fast, ordered and visual overview of the contributions". The feature of adding comments to designs (k) was also perceived as very useful (by the $91 \%, 9 \%$ found it "useful"). Participants also valued that the starters received the notifications about the new comments in their e-mail. However, in this case this feature had been used fewer times than in the previous one. Users made several proposals to enhance this feature that are related to the intrinsic functionalities of the editors (eventually) integrated in LdShake.

According to $82 \%$ of the participants in this case, LdShake facilitated the devising of co-creative, innovative or rich ideas to a large $(64 \%)$ or some $(18 \%)$ extent. For some of them, the strongest aspect of LdShake is the social network orientation of the system that enables a small community of colleagues to be aware and interact around the research ideas undertaken by others; "It's eye-opening to see the work of others within a community specifically devoted to a topic". For others, providing co-editing support and not only social sharing of ideas represented a relevant added value; "The most positive aspect is that the system enables co-editing and not only sharing". All in all, participants indicated that the tool serves as a flexible knowledge management tool for the research team that also fosters the identification of innovative joint research lines between different team members exploiting synergies. Users' proposals for extensions in this case included awareness features, such as a notification system to inform about new designs, changes in existing designs and indications about which users are on-line.

\subsection{Discussion}

This section has presented two contexts where LdShake has been applied to address virtual networked team formation, storage and retrieval of designs exchanged and generated in the platform, and interaction in co-editing processes. The results of each context provide some lessons learnt about the support of LdShake technological features for these purposes in two contexts. The first context is focused on supporting learning design on-line teamwork, the specific scope for which the LdShake tool has been specifically designed. In this context, the participants were individuals interested in Education and Media Communication that are currently coursing a Master in this topic. In the second context, the knowledge shared and co-created had to do with research ideas. The behaviour and opinions of the participants in the two cases confirm the usefulness and usability of most LdShake technological features to support networked team requirements. Moreover, it is interesting to note that the behaviour of the participants differed in the use of some of these features due to the different timescale of the cases and the characteristics of the distinct contexts. In the first context devoted to learning design, and that took place for a shorter period of time, users made more daily visits to the site and its pages per day than in the second case. In addition, their time-on-site was also significantly higher.

In both cases users made extensive use of some of the LdShake technological features devoted to support team formation. In the majority of the occasions users created teams that could interact with the designs (either editing or reading them) via the sharing of the designs. Besides, some users decided to predefine their own named groups so that they could reuse these groups when sharing several designs with the same teams of LdShakers. This feature has been used more in the research team case because it was clearer for the participants in this context which members of the community would be 
interested in interacting with them and elaborating diverse joint research ideas. For the participants of the learning design case, the arrangement of teams seemed to be more dependent on the topic of each specific design. In both cases being able to see the list and profiles of the LdShakers in the system was of significant relevance with respect to fostering interpersonal trust and identifying shared affinities. The majority of the participants in the two cases felt comfortable with the sharing policies implemented in LdShake, which can be summarized in two principles: the starter decides the sharing access rights, and there is a differentiation between editing and reading group of users for each design. In both cases a large number of small teams were formed to collaboratively edit designs, and most designs were also shared with reading access rights with the whole community in LdShake.

The storage and retrieval of designs exchanged and generated by the teams in the two contexts were supported mainly by the organization of the designs into sections: designs that users can edit ("My $L_{d S}$ "), designs that they can just read ("Browse LdS"), and LdShakers starting designs. The success of this latter feature shows again the importance of the social network orientation to support this type of networked interaction. Probably because the number of designs in the system was not large, users did not often use the filtering options found in "My LdS" ("Created by me" and "Shared with me"). On the other hand, the tags that starters could add when creating an LdS were perceived as useful to classify the LdS by topic. However, the evaluation results make clear that the implementation of the tagging approach should be redesigned in order to better facilitate retrieval. Interestingly, the difference between the use of "My LdS" in comparison to "Browse LdS" is significant. In the learning design case, participants tended to explore the designs by using the "Browse LdS" section so as to see both the designs they could read and edit. In this context it appeared that users were highly interested in learning from other designs created by their peers. In contrast, in the research team case, participants tended to use more the "My LdS" section, which is an indicator that research team members had a tendency to be more interested in those designs in which they were expected to directly contribute to than in the designs belonging to other small teams within the research group.

Two main technological features fostered interactions in the two contexts. The first feature is the history record about each LdS, which is graphically shown to starters and editors and enables a visual navigation through the changes. On the one hand, the contributions of each user can be identified and socially recognized by the team members while, on the other hand, starters and contributors can reflect on the design co-editing process and have the confidence that any previous version of the LdS can be recovered, if necessary. The second feature is about adding comments to the LdS, both by editors and readers of the designs. It is noteworthy that this facility was largely used in the learning designs case and valued quite positively in both contexts.

\section{Conclusions}

LdShake is a social network-oriented platform that provides an integrated environment for the teambased sharing and co-editing of learning designs within small communities of users. LdShake provides a solution to support educational innovation initiatives that require educators and other stakeholders within institutions, or thematically across institutions, to team up and collaborate in learning designs. It is the creator of a design who decides the formation of the team working on the co-editing of the design and whether other registered users in the system will be able to see the design and post comments to it. The technological features of LdShake provide a support that goes beyond the sharing of design ideas and enables the co-authoring of designs. Those designs can be created with several existing web editors integrated in LdShake, adopting its technological features (such as WebCollage, eXeLearning and a rich text editor). This paper has described in detail the technological features of LdShake that satisfy learning design networked team requirements, including team formation, the storage and retrieval of (shared) designs and the enabling and promoting of interaction in the design co-creation process.

These features have been used and evaluated in two distinct contexts, namely, the conception and sharing of learning designs and research ideas. Though the first context is more authentic and takes into account the target use of LdShake, the study of both contexts has provided interesting and complementary results about the adequacy of the LdShake features for the support of networked teams. Though the behaviour of the participants in the use of some of the facilities differed because of the characteristics of each context, in general it is possible to say that the social network-oriented aspects implemented in the platform (designs as shared social objects, visualizing list of users, browsing LdS by creator, different access rights to the social objects, organizing the LdS according to the access rights) have proved to be successful in the facilitation of team formation as well as the storage and 
retrieval of the designs. Besides, the support for graphical history browsing and the addition of comments have shown to foster interaction.

In addition to the aspects for improvement identified in the evaluation results of the two contexts, future features to be implemented in the system include the enhancement of group management functionalities. These functionalities will enable rearrangement and disbandment of team formation with optional retroactive effects to some of the designs that were previously assigned to a team, as well as the possibility of copying the sharing settings of another design. The listings can also be enriched with different ordering options to further facilitate the retrieval of designs. A planned development in this way is ordering designs using a "relevance" metric. The calculation of this metric is still under definition, but it will include user ratings and social indicators such as number of revisions made by different users or number of comments. This ordering also represents a reward or incentive for networked teams and is expected to motivate users' participation fostering increasingly fruitful interactions. Further evaluation experiences in realistic scenarios of different time-scales will be carried out to evaluate the enhanced features being implemented in LdShake.

\section{Acknowledgements}

The authors would like to thank to all of the participants in the two studies, to the referees and special issue guest-editors for their constructive comments, to Miguel Angel Carralero for his support and ideas, and to Lauren Romeo and Jose G. Alvarado for proofreading the final version of this paper. This work has been partially funded by the Learn3 (TIN2008-05163/TSI) and EEE (TIN2011-28308-C03-03) projects.

\section{References}

AUTC. (2003). Learning designs, products of the AUTC project on ICT-based learning designs. Retrieved March 2012, from http://www.learningdesigns.uow.edu.au

Berlanga, A. J., Sloep, P., Brouns, F., Van Rosmalen, P., Bitter-Rijpkema, M., \& Koper, R. (2007). Functionality for learning networks: lessons learned from social web applications. Proceedings of the ePortfolio 2007 Conference, Maastricht, The Netherlands.

Cairns, P., \& Cox, A. L. (2008). Research methods for human-computer interaction. Cambridge: Cambridge University Press.

Calvo, R.A., O'Rourke, S.T, Jones, J., Yacef, K., \& Reimann, P. (2011). Collaborative writing support tools on the Cloud. IEEE Transactions on Learning Technologies, 4(1), 88-97.

Carrió, M., Larramona, P., Baños, J. E., \& Pérez, J. (2011). The effectiveness of the hybrid problem-based learning approach in the teaching of biology: a comparison with lecture-based learning. Journal of Biological Education, 45(4), 229-235.

Cifuentes, L., Sharp, A., Bulu, S., Benz, M., \& Stough, L. M. (2009). Developing a web 2.0-based system with userauthored content for community use and teacher education. Educational Technology Research and Development, 58(4), 377-398.

Conole, G. (forthcoming). Designing for learning in an Open World, New York: Springer.

Davis, H. C., Carr, L., Hey, J. M. N., Howard, Y., Millard, D., Morris, D., et al. (2010). Bootstrapping a culture of sharing to facilitate open educational resources. IEEE Transactions on Learning Technologies, 3(2), 96-109. GLOW. Scotland intranet for education. Retrieved March 2012, from http://www.ltscotland.org.uk/glowscotland/index.asp

Goddard, Y. L., Goddard, R. D., \& Tschannen-Moran, M. (2007). A theoretical and empirical investigation of teacher collaboration for school improvement and student achievement in public elementary schools. Teachers College Record, 109(4), 877-896.

Griffiths, D., \& Blat, J. (2005). The role of teachers in editing and authoring units of learning using IMS Learning Design. Advanced Technology for Learning, Special Issue on Designing Learning Activities: From Content-Based to Context-Based Learning Services, 2(4), 243-251.

Guba, E. G. (1981). Criteria for assessing the trustworthiness of naturalistic inquiries. Educational Communication and Technology: A Journal of Theory, Research, and Development, 29(2), 75-91.

Hernández-Leo, D., Abenia, P., Moreno, P., Chacón, J., \& Blat, J. (2001a). Let's shake on it: can we support co-edition and sharing using diverse learning design editors within the same platform? The Art \& Science of Learning Design Workshop, LKL, London, 13-14 October 2011.

Hernández-Leo, D., Romeo, L., Carralero, M.A., Cachón, J., Carrió, M., Moreno, P., \& Blat, J. (2011b). LdShake: Learning design solutions sharing and co-edition. Computers \& Education, 57(4), 2249-2260.

Knorr-Cetina, K. (1997). Sociality with objects: Social relations in postsocial knowledge societies. Theory, Culture \& Society, 14(4), 1-30. 
Kozma, R. B. (2003). Technology and classroom practices: An international study. Journal of Research on Technology in Education, 36(1), 1-14.

Lope, S. (2009). L'experimentació a l'aula del projecte "Biologia en context": La mirada del professorat. Ciències: Revista Del Professorat De Ciències De Primària i Secundària, (14), 18-20.

Michelson, W., \& Harvey, A. S. (2000). Is Teachers' Work Never Done?: Time-Use and Subjective Outcomes. Journal of Radical Pedagogy, 2(1), available on-line at http://radicalpedagogy.icaap.org/content/issue2_1/.

Morse, J. M. (2003). Principles of mixed methods and multimethod research design. In A. Tashakkori., \& C. M. Teddlie (Eds.), Handbook of mixed methods in social \& behavioural research (pp. 189-208). Thousand Oaks, CA, USA: Sage publications, Inc.

Neumann, S., Klebl, M., Griffiths, D., Hernández-Leo, D., Fuente, L., Hummel, H., et al. (2010). Report of the results of an IMS learning design expert workshop. International Journal of Emerging Technologies in Learning, 5(1), 58-72.

Neuwirth, C. M., Kaufer, D. S., Chandhok, R., \& Morris, J. H. (1990). Issues in the design of computer support for coauthoring and commenting. ACM Conference on Computer-Supported Cooperative Work, Los Angeles, CA, USA. 183-195.

Phoebe. Pedagogic planer. Retrieved March 2012, from http://www.phoebe.ox.ac.uk/

Sarasa, A., Canabal, J. M., \& Sacristán, J. C. (2009). Agrega: A distributed repository network of standarized learning objects. 10th International Work-Conference on Artificial Neural Networks, Salamanca, Spain. 466-474.

Williams, I., \& Thorpe, R. (1998). Small primary schools in rural Wales: Frameworks of collaboration. Journal of Research in Rural Education, 13(3), 161-171. 